\title{
GIARDIA INTESTINALIS AND HELICOBACTER PYLORI CO-INFECTION: ESTIMATED RISKS AND PREDICTIVE FACTORS IN EGYPT
}

\author{
By \\ AYMAN A. EL-BADRY ${ }^{1}$, MARWA A. GHIETH ${ }^{2}$, DOAA A. AHMED ${ }^{3}$ \\ AND MOUSA A.M. ISMAIL ${ }^{1}$
}

Department of Medical Parasitology ${ }^{1}$, Faculty of Medicine, Cairo University, Cairo, Department of Medical Parasitology ${ }^{2}$, Faculty of Medicine, Beni-Suef University, Beni-Suef, Department of Medical Parasitology ${ }^{3}$, Faculty of Medicine for Girls, Al-Azhar University, Nasr City, Egypt ( ${ }^{*}$ Correspondence: marwaghieth@yahoo.com)

\section{Abstract}

Giardia intestinalis (G. intestinalis) and Helicobacter pylori (H.pylori) are two intestinal pathogens sharing the same mode of infection. This study determines the prevalence of G. intestinalis and H. pylori co-infection estimated risks and predictive factors for susceptibility to co-infection. Stool samples were collected from 801 patients suffering gastrointestinal symptoms and living in Greater Cairo. They were subjected to coproscopic examination for detection of intestinal parasites and copro PCRrestriction fragment length polymorphism (PCR-RFLP) and sequencing targeting the glutamate dehydrogenase (gdh) gene for Giardia. Positive samples for giardiasis were further subjected to coproimmunoassay to detect $H$. pylori coprontigen. Among 63 cases of giardiasis by both microscopy and PCR (84.1\% as-semblage B and $15.9 \%$ AII), $52.5 \%$ were co-infected with $H$. pylori. Co-infection was more frequent with assemblage B (50.9\%) than assemblage A (40\%). Among studied variables of assemblage type, gender, or harboring more than one parasite (polyparasitism), only school age children, was signifi-cantly associated ( $P$ value: 0.02 ) with Giardia and $H$. pylori co-infection. Physicians in Egypt must consider $G$. intestinalis and $H$. pylori as prevailing intestinal pathogens with predominance of Giardia assemblage B. Giardia and H. pylori co-infection is common in school aged children and modulates gastrointestinal manifestations. Intestinal parasitism and $H$. pylori association is complex and necessitates further genomic studies for a better understanding of the epidemiological and clinical impact of co-infection, as well as possible strategies for their treatment and control.

Key words: Giardiasis, Helicobacter, co-infection, PCR-RFLP, gdh, immunochromatograpghy

\section{Introduction}

The protozoan $G$. intestinalis is the most common and vital intestinal protozoan (Thompson, 2004). The disease is characterized by number of gastrointestinal symptoms, diarrhea, abdominal pain, flatulence and Malnutrition (Veenemans et al, 2011). The source of infection is through oral rout (Thompson and Monis, 2012). Mostly human infections are related to assemblage A and $\mathrm{B}$, the latter is often the most prevalent assemblage in human (Fahmy et al., 2015).

H. pylori is a gram negative, microaerophilic bacillus, which colonizes the gastric mucosa giving variations of clinical manifestation ranging from dyspepsia, ulcer and pain till gastric cancer (Gatta et al, 2013). The disease often is acquired during early childhood and could persist throughout life as it is widespread intra-familial and from mother to child (Osaki et al., 2015). For detection of
$H$. pylori copro-antigen, the use of monoclonal antibodies via immunochromatographic technique is a non-invasive diagnostic test with high sensitivity and specificity (Sato et al., 2012; Okuda et al., 2014).

H.pylori produces a urease causing a state of diminished gastric acidity, a condition which is favored by the parasite Giardia (David and William, 2006). In addition, the two organisms share the same route of infection mainly the feco-oral one (Moreira et al., 2005). Many studies had discussed the association between giardiasis and $H$. pylori and its impact on each organism (Moreira et al, 2005; Grazioli et al, 2006; Zeyrek et al, 2008; Isaeva and Efimova 2010; Júlio et al, 2012). The present study aimed to detect the prevalence of co-existence of giardiasis and H. pylori in Egyptian patients and to estimate risks and predictive clinical factors for this co-infection. 


\section{Materials and Methods}

Study design and populations: A cross sectional study was conducted including 801 patients from greater Cairo suffering from gastrointestinal symptoms. Collected faecal samples were done after informing the adult patients and the parents of young children about the purpose of the study and informed consent was obtained.

Collection and processing of sample: Single stool sample was collected from each patient and divided into three parts, one for coproscopic examination using saline and Lugol's iodine stained direct wet mount before and after formalin-ethyl acetate concentration to detect G.intestinalis and other parasites. The other two parts were freshly frozen at $-20{ }^{\circ} \mathrm{C}$ for copro immuno-molecular assays at Lab of Molecular Medical Parasitology (LMMP), Faculty of Medicine, Cairo University.

Copro immunoassay: Positive stool samples for Giardia by microscopy were exposed to $H$. pylori coproantigen detection using chromatographic immunoassay, the On Site H. pylori Ag Rapid Test (CTK Biotech, USA).

Copro-PCR assay: All samples were subjected to genomic DNA extraction using Favor Prep stool DNA isolation Kit (Favorgen Biotech corporation ping-Tung 908, Taiwan), according to the manufacturer's instruction. A semi-nested PCR (nPCR) was done targeting the gdh gene, using GDHeF: 5' TCAACGTYAAYCGYGGYTTCCGT 3' and GDHiR: 5' GTTRTCCTTG CACATCT CC 3 ' primers for first PCR, GDHiF: 5' CA GTACAACTCYGCTCTCGG 3', and GDH iR for semi-nested PCR. The reaction mixture and conditions were performed (Read et $a l$, 2004). The amplified products were stained by ethidium bromide and visualized with $1.5 \%$ agarose gel electrophoresis.

PCR-RFLP of gdh: The PCR products were digested by two enzymes NIa IV (New England Biolabs. 0141210) which discriminates between AI, AII, B, C, D and E assemblages, and RSaI enzyme (New England
Biolabs, FD1124) to differentiate assemblage BIII and BIV according to the manufacturer's instructions. Restriction profiles were visualized on $2 \%$ agarose gel electrophoresis stained with ethidium bromide.

Sequencing: PCR-RFLP results were confirmed by sequencing using Qiagen PCR purification kit (QIAGEN, Hilden, Germany) according to the manufacturer's instructions, the amplified products were purifand visualized on $1.5 \%$ agarose gel electrophoresis. Sequencing was performed with BigDye ${ }^{\circledR}$ Terminator v3.1, Ready Reaction Cycle Sequencing Kit (Applied Biosystems, Foster City, CA) for semi-nested PCR products. Post sequencing reaction products were cleaned using Big Dye $\mathrm{X}$ purification kit (Applied Biosystems, Foster City, CA) according to the manufacturer's instructions. DNA template sequencing was performed on an ABI Prism 310 genetic analyzer (Applied Biosystems, Foster City, CA).

Statistical analysis: Statistical package for social sciences (SPSS) version 20 was used for statistical analysis. Descriptive data was analyzed by mean \pm standard deviation, while qualitative data was analyzed by frequencies. Co-infection of giardiasis and H.pylori was the dependent variable and chisquare test was used to assess their association with each other and with the independent variables: age, sex, polyparasitism, and Giardia assemblages. These variables were estimated risks, while clinical symptoms were predictive factors. The odds ratio (OR) and $95 \%$ confidence interval (CI) were calculated for each of the variables by logistic regression model. The student $\mathrm{T}$ test and mean of age was used to estimate age as a risk factor by comparing patients co-infected with giardiasis and H.pylori with patient with Giardia infection.

\section{Results}

The study included 801 patients with age ranged from 2 to 60 years old with mean of 14.5 \pm 7.93 . The microscopic prevalence of Giardia was about $10 \%(\mathrm{n}=80)$, among them 63 samples were successfully amplified by 
semi-nested PCR and genotyped by PCRRFLP and sequencing using gdh gene. Giardia assemblage B and A $(84.1 \%, 15.9 \%$, respectively) were detected. Subgenotyping of assemblage B was, BIII, BIV (49.1\%, $22.6 \%$, respectively) and $28.3 \%$ of assemblage B was not subgenotyped (Tab. 1), and all assemblage A samples were AII.

$H$. pylori and $G$. intestinalis frequency and risk factors: The co-infection prevalence of

Table 1: Demographic and clinical data of individuals.

\begin{tabular}{|c|c|c|}
\hline \multicolumn{2}{|l|}{ Variables } & $\mathrm{n}(\%)$ \\
\hline \multicolumn{2}{|l|}{ Age group (years old) } & \\
\hline \multicolumn{2}{|l|}{ Up to 2} & $38(4.7)$ \\
\hline \multicolumn{2}{|l|}{$>2-6$} & $240(29.9)$ \\
\hline \multicolumn{2}{|l|}{$>6-12$} & $216(26.6)$ \\
\hline \multicolumn{2}{|l|}{$>12-20$} & $136(17)$ \\
\hline \multicolumn{2}{|l|}{$>20-30$} & $114(14.2)$ \\
\hline \multicolumn{2}{|l|}{$>30-40$} & $46(5.7)$ \\
\hline \multicolumn{2}{|l|}{$>40-50$} & $0(0)$ \\
\hline \multicolumn{2}{|l|}{$>50-60$} & $12(1.5)$ \\
\hline & $432(53.9)$ \\
\hline & Female & $370(46.1)$ \\
\hline \multirow{5}{*}{ Clinical examination } & Pain & $238(29.6)$ \\
\hline & Flatulence & $124(15.5)$ \\
\hline & Diarrhea & $414(51.6)$ \\
\hline & Fatigue & $178(22.2)$ \\
\hline & Vomiting & $22(2.7)$ \\
\hline \multicolumn{2}{|l|}{ Polyparasitism } & $60(15)$ \\
\hline \multicolumn{2}{|c|}{ Microscopic examination } & \\
\hline \multicolumn{2}{|c|}{ Giardia cyst/trophozoite } & $80(10.0)$ \\
\hline \multicolumn{2}{|c|}{ Entamoeba complex cyst/trophozoite } & $21(2.6)$ \\
\hline \multicolumn{2}{|c|}{ Entamoeba coli cyst } & $23(2.87)$ \\
\hline \multicolumn{2}{|l|}{ Blastocystis spp. } & $11(1.37)$ \\
\hline \multicolumn{2}{|l|}{ Iodamoeba butschlii } & $4(0.5)$ \\
\hline \multicolumn{2}{|l|}{ Hymenolepis nana } & $16(1.99)$ \\
\hline \multicolumn{2}{|c|}{ Taenia eggs } & $6 \quad(0.7)$ \\
\hline \multicolumn{2}{|c|}{ Enterobius vermicularis } & $4 \quad(0.5)$ \\
\hline \multicolumn{2}{|l|}{ Ascaris lumbricoides } & $2 \quad(0.25)$ \\
\hline
\end{tabular}

Table 2: Distribution of $H$. pylori coproantigen cases among Giardia assemblages

\begin{tabular}{|c|c|c|c|c|c|c|c|}
\hline & \multicolumn{3}{|c|}{ H.pylori copro antigen } & \multirow{2}{*}{$\begin{array}{c}P \\
\text { value }\end{array}$} & \multirow[b]{2}{*}{ OR } & \multirow[b]{2}{*}{$95 \% \mathrm{CI}$} \\
\hline & & $\begin{array}{c}\text { positive } \\
(\mathrm{n}=42)\end{array}$ & $\begin{array}{c}\text { negative } \\
(\mathrm{n}=38)\end{array}$ & Total & & & \\
\hline \multirow{3}{*}{$\begin{array}{l}\text { Giardia } \\
\text { assemblage }\end{array}$} & $B(n=53)$ & $27(50.9 \%)$ & $26(49.1 \%)$ & $53(66.2 \%)$ & 0.44 & 1.20 & $0.48-3.05$ \\
\hline & $\mathrm{A}(\mathrm{n}=10)$ & $4(40 \%)$ & $6(60 \%)$ & $10(12.5 \%)$ & 0.31 & 1.78 & $0.46-6.86$ \\
\hline & Not-typed $(n=17)$ & $11(64.7 \%)$ & $6(35.3 \%)$ & $17(21.3 \%)$ & 0.19 & 1.89 & $0.62-5.74$ \\
\hline
\end{tabular}

$\mathrm{OR}=$ Odds ratio, $95 \% \mathrm{CI}=95 \%$ confidence interval

Table 3: Mean age among Giardia and $H$. pylori patients.

\begin{tabular}{|c|c|c|c|}
\hline & Mean of age & $P$ value & 95\% CI \\
\hline Co-infection (Giardia + H.pylori) $(\mathrm{n}=42)$ & $9.833 \pm 8.9815$ & \multirow{2}{*}{$0.02 *$} & $0.728-6.058$ \\
\cline { 1 - 2 } Non co-infection $($ Giardia only) $(\mathrm{n}=38)$ & $7.168 \pm 5.7219$ & & $0.662-5.991$ \\
\hline
\end{tabular}

$*$ Significant $p$ value $(<0.05)$
H.pylori and giardiasis was $52.5 \%(\mathrm{n}=42)$, pylori positive coproantigen was more assemblage B $(50.9 \%)$ than nificance. The mean age of co-infected patients was 9.8 \pm 8.98 , with significant association $(P$ value $=0.02)$ (tTabs. 2,3$)$. None variated with co-infection. ables other than age was significant associ- 
Table 4: Giardia and H.pylori co-infection, estimated risks and predictive clinical symptoms.

\begin{tabular}{|c|c|c|c|c|c|}
\hline \multirow{2}{*}{\multicolumn{2}{|c|}{ Variable }} & \multicolumn{4}{|c|}{ Co-infection $(\mathrm{n}=42)$} \\
\hline & & No. & $(\%)$ & $P$ value & OR $(95 \% \mathrm{CI})$ \\
\hline \multicolumn{2}{|l|}{ Age group (years old) } & & & & \\
\hline \multicolumn{2}{|l|}{ Up to 2} & 4 & 9.5 & & \\
\hline \multicolumn{2}{|l|}{$>2-6$} & 16 & 38.1 & & \\
\hline \multicolumn{2}{|l|}{$>6-12$} & 11 & 26.2 & & \\
\hline \multicolumn{2}{|l|}{$>12-20$} & 3 & 7.1 & 0.695 & - \\
\hline \multicolumn{2}{|l|}{$>20-30$} & 7 & 16.7 & & \\
\hline \multicolumn{2}{|l|}{$>30-40$} & 1 & 2.4 & & \\
\hline \multirow{2}{*}{ Sex } & Male & 20 & 47.6 & \multirow{2}{*}{0.176} & \multirow{2}{*}{$1.69(0.69-4.10)$} \\
\hline & Female & 22 & 52.4 & & \\
\hline \multirow{5}{*}{ Clinical examination } & Abdominal Pain & 20 & 47.6 & 0.176 & $0.59(0.24-1.44)$ \\
\hline & Flatulence & 16 & 38.1 & 0.354 & $1.34(0.53-3.36)$ \\
\hline & Diarrhea & 31 & 73.8 & 0.595 & $1.01(0.37-2.73)$ \\
\hline & Fatigue & 11 & 26.2 & 0.489 & $0.87(0.33-2.33)$ \\
\hline & Vomiting & 4 & 9.5 & 0.557 & $1.23(0.26-5.88)$ \\
\hline \multicolumn{2}{|l|}{ Polyparasitism } & 23 & 54.8 & 0.083 & $2.08(0.85-5.09)$ \\
\hline
\end{tabular}

\section{Discussion}

In the present study, there was assemblage B $(84.9 \%)$ predominance both for the entire study group and for the subgroup of coinfected patients, similar to previous reports of many Egyptians studies (Helmy et al, 2014; Fahmy et al, 2015; Ghieth et al, 2016). The source of Giardia infection in a region can be determined by the assemblage profile as it is an extremely diverse organism with a variety of assemblage and subassemblage styles (Feng and Xiao, 2011). The predominance of anthroponotic Giardia assemblages (B \& AII) in the studied population, suggested that man was the source of infection rather than zoonotic. The coinfection prevalence of $H$. pylori and giardiasis was $52.5 \%, H$. pylori positive coproantigen was more in assemblage B (50.9\%) than assemblage A (40\%), while Giardia type assemblage was not a risk factor for the association. Infection with $H$. pylori and $G i$ ardia were a reflection of socio-environmental levels (Patterson et al, 2012). Developing countries showed a higher colonization level than developed ones (Vale and Vitor, 2010; Hasosah et al, 2015).

The high occurrence rate of $H$. pylori $(52.5 \%)$ in patients with positive giardiasis in the results supported the theory that conditions for Giardia survival are heightened by the bacterium $H$. pylori. A much higher rate of co-infection was observed in Iran by Shafie et al. (2009) who found that all Giardia positive patients were infected with $H$. pylori. Studies differ in explaining which organism was agonist in the presence of the other, Júlio et al. (2012) reported that the presence of $H$. pylori infection was a risk factor for giardiasis, and Moreira et al. (2005) mentioned that, $H$ pylori infection was significantly associated with G. lamblia.

The present study showed that late childhood was the most vulnerable age group $(9.8 \pm 8.98)$ for co-infection, with statistical significance $(P$ value $=0.02)$, while Giardia infection alone was more prevalent in preschool age children. Bin Mohanna et al. (2014) also reported higher prevalence of co-infection in late childhood, and for $H$. pylori infection the age above 10 was a risk factor (Hasosah et al, 2015). In contrast Ankarklev et al. (2012) reported a higher prevalence of co-infection for a younger age group (3-5 years old). Giardiasis usually affects 2-6 year old children, while coinfection with $H$. pylori causes giardiasis to reach a peak at an older age. This can be explained by the fact that $H$. pylori create favorable conditions for the sustenance of $G i$ ardia colonization.

In the present study, co-infection was associated with polyparasitism (other than $\mathrm{Gi}^{-}$ ardia) in more than half of patients and was more prevalent in females $(52.4 \%)$ than males, without statistical significance. The results showed that, diarrhea and abdominal pain were most frequent $(73.8 \%, 47.6 \%$, respectively) while vomiting was least present (9.5\%), however no clinical symptoms were 
predictive for co-infection. There is controversy concerning association between $G$. intestinalis and $H$. pylori co-infection and clinical symptoms. Zeyrek et al. (2008) in Turkey reported that such association has an impact on patients with recurrent abdominal pain. Others reported that gastric colonization by Giardia was preceded by $H$. pylori (Doglioni et al, 1992; Moreira et al, 2005). A significant association was found between the two infections in patients with irritable bowel diseases by Grazioli et al. (2006).

In Egypt Kader et al. (1998) in Ain-Shams University's Hospitals examined thirty patients treated with proton pump inhibitor but had symptoms related to gastritis or peptic ulcers to upper gastrointestinal endoscopy and gastric biopsy for giardiasis. They reported gastric giardiasis in $3(10 \%)$ cases of intestinal metaplasia and $H$. pylori in all cases, and concluded that there might be a relation between the presence of gastric giardiasis and the intake of proton pump inhibitor and that endoscopists have to search for gastric giardiasis especially in $H$. pylori and/or intestinal metaplasia. Abou Holw et al. (2009) in Alexandria reported that giardiasis was one of the most common enteroprotozoal diseases associated with $H$. pylori. Among fifty patients parasitologically proven giardiasis cases and ten normal healthy controls, they found significant upper gastrointestinal symptoms (epigastric pain and anorexia) in giardiasis patients with $\mathrm{H}$. pylori. Also, endoscopic and histopathologic examination showed significant gastric lesions in this group of patients as compared to those suffering only G. lamblia. Eldash et al. (2013) in Al-Fayoum evaluated the incidence of $\mathrm{H}$. pylori and G. intestinalis co-infection in RAP Egyptian among 90 children and 90 crossmatched healthy controls. H. pylori (HP) infection was diagnosed by detection of HP stool antigen (HPSA), ELISA and/or HP antibody (IgG), ELISA in serum, while $G$. intestinalis by stained stool smears. The HP infection was detected in $60(66.7 \%)$ patients and $37(41 \%)$ controls with a signifi- cant difference $\mathrm{p}=0.001$. Giardiasis was found in $47(52.2 \%)$ patients and $30(33.3 \%)$ controls with a significant difference $\mathrm{p}=$ 0.02 . Incidence was higher among children above 5 years, as a significant predictor for RAP. They concluded that recurrent abdominal pain affected $10-20 \%$ of schoolaged children due to coinfection with $H$. pylori and $G$, intestinalis as organic causes.

\section{Conclusion}

Assemblage B and AII were the profiles of giardiasis in symptomized patients at Great Cairo. H. pylori coexisted in more than half of patients infected with giardiasis, it was more frequent with assemblage $\mathrm{B}$. it is recommended in giardiasis patients with the age of late childhood and early young to do an easy, none invasive $H$. pylori coproantigen test. None of assemblage type, gender or polyparasitism was risk factors for such coinfection.

\section{Acknowledgements}

The authors are grateful to the Scientific Research Developing Unit, Beni-Suef University, for funding and granting this work, also, the Lab of Molecular Medical Parasitology (LMMP), Faculty of Medicine, Cairo University for processing of the protocol.

\section{References}

Abou Holw, SA, Anwar, MM, Heshmat, MG, Enany, AY, Rashad, MM, 2009: Effect of concommitant Helicobacter pylori infection in patients with Giardiasis lamblia in Egypt. J. Egypt. Soc. Parasitol. 39, 2:439-46.

Ankarklev, J, Hestvik, E, Lebbad, M, Lindh J, Kaddu-Mulindwa, DH, Andersson JO, et al, 2012: Common coinfections of Giardia intestinalis and Helicobacter pylori in non-symptomatic Ugandan children. PLoS Negl. Trop. Dis. 6:1780.

Bin Mohanna, MA, Al-Zubairi, LM, Sallam, AK, 2014: Prevalence of Helicobacter pylori and parasites in symptomatic children examined for Helicobacter pylori antibodies, antigens, and parasites in Yemen. Saudi Med. J, 35:1408-11.

David, TJ; William, AP, 2006: Markell and Voge's Medical Parasitology. $9^{\text {th }}$ ed.; Saunders Elsevier, New York.

Doglioni, C, De Boni, M, Cielo, R, Laurino, L, 
Pelosio, P, Braidotti, P, Viale, G, 1992: Gastric giardiasis. Clin Pathol. 45, 11:964-7.

Eldash, HH, Bekhit, OE, Algameel, AA, 2013: Impact of Helicobacter pylori-giardiasis coinfection on children with recurrent abdominal pain. J. Egypt. Soc. Parasitol. 43, 2:509-16.

Fahmy, HM, El-Serougi, AO, El Deeb, HK, Hussein, HM, Abou-Seri, HM, Klotz, $C$ et al, 2015: Giardia duodenalis assemblages in Egyptian children with diarrhea. Eur. J. Clin. Microbiol. Infect. Dis. 34, 8:1573-81

Feng, Y, Xiao, L, 2011: Zoonotic potential and molecular epidemiology of Giardia species and giardiasis. Clin. Microbiol. Rev. 24, 1:110-40.

Gatta, L, Vakil, N, Vaira, D, Scarpignato, C, 2013: Global eradication rates for Helicobacter pylori, systematic review and meta-analysis of sequential therapy. BMJ 347:4587-90.

Ghieth, MA, El-Badry, AA, Abu-Sarea, EY, Abdel Gawad, SS, Elsharkawy MM, 2016: Genotypic analysis of Giardia duodenalis in children at Egypt. Comp Clin. Pathol. 25, 6: 1241-6.

Grazioli, B, Matera, G, Laratta, C, Schipani, G, Guarnieri, G, et al, 2006: Giardia lamblia infection in patients with irritable bowel syndrome and dyspepsia: A prospective study. World J. Gastroenterol. 12, 12:1941-4.

Hasosah, M, Satti, M, Shehzad, A, et al, 2015: Prevalence and risk factors of Helicobacter pylori infection in Saudi children: a three-year prospective controlled study. Helicobacter 20:5663.

Helmy, YA, Klotz, C, Wilking, H, Krücken, J, Nöckler, K, Von Samson- Himmelstjerna, G, et al, 2014: Epidemiology of Giardia duodenalis in ruminant livestock and children in the Ismailia province of Egypt: insights by genetic characterization. Parasit. Vectors 7, 1:321-7.

Isaeva, G, Efimova, NG, 2010: Gastrointestinal giardiasis associated with Helicobacter pylori. Eksp. Klin. Gastroenterol. 12:30-34.

Júlio, C, Vilares A, Oleastro, M, Ferreira, I, Gomes, S, et al, 2012: Prevalence and risk factors for Giardia duodenalis infection among children: A case study in Portugal. Parasites \&Vectors 2012 5:22. Parasites \& Vectors 5:22 doi: 10.1186/1756-3305-5-22.

Kader, SA, Mansour, AM, Mohran, Z, el-Taoil, A, Abdalla, KF, 1998: A study on the relation between proton pump inhibitor and gastric giardiasis. J. Egypt. Soc. Parasitol. 28, 1:149-57.
Moreira, ED, Jr, Nassri, VB, Santos, RS, Matos, JF, et al, 2005: Association of Helicobacter pylori infection and giardiasis: results from a study of surrogate markers for fecal exposure in children. Wld. J. Gastroenterol. 11:2759-63.

Okuda, M, Osaki, T, Kikuchi, S, Ueda, J, Lin, Y, et al, 2014: Evaluation of a stool antigen test using a mAb for native catalase for diagnosis of Helicobacter pylori infection in children and adults. J. Med. Microbiol. 63:1621-5.

Osaki, T, Konno, M, Yonezawa, H, Hojo, F, Zaman, C, et al, 2015: Analysis of intra-familial transmission of Helicobacter pylori in Japanese families. J. Med. Microbiol. 64:67-73.

Patterson, T, Straten, E, Jimenez, S, 2012: Prevalence of Helicobacter pylori antibody in different age groups in Central Texas. Clin. Lab. Sci. 25:102-6.

Read, CM, Monis, PT, Thompson, RA, 2004: Discrimination of all genotypes of Giardia duodenalis at glutamate dehydrogenase locus using PCR-RFLP. Infect. Genet. Evol. 4, 2:125-30.

Sato M, Shimoyama T, Takahashi R, Kajiyama $\mathrm{H}$, Sano $\mathrm{Y}$, et al, 2012: Characterization and usefulness of stool antigen tests using a monoclonal antibody to Helicobacter pylori catalase. J. Gastroenterol. Hepatol. 27, 3:23-8.

Shafie, R, Jahani, MR, Rezaeian, M, Amini, M, Metvayi, AR et al, 2009: Giardia lamblia and Helicobater pylori Coinfection Iranian. J. Publ. Hlth. 38, 1:127-30

Thompson, RC, 2004: The zoonotic significance and molecular epidemiology of Giardia and giardiasis. Vet. Parasitol. 126:15-35

Thompson, RC, Monis, P, 2012: Giardia, from genome to proteome. Adv. Parasitol. 78:57-95.

Vale, FF, Vitor, JM, 2010: Transmission pathway of Helicobacter pylori: does food play a role in rural and urban areas? Int. J. Food. Microbiol. 138:1-12.

Veenemans, J, Mank, T, Ottenhof, M, Baidjoe, A, Mbugi, EV, et al, 2011: Protection against diarrhea associated with Giardia intestinalis is lost with multi-nutrient supplementation: a study in Tanzanian children. PLoS. Negl. Trop. Dis 5, 6:1158.

Zeyrek, D, Zeyrek, F, Cakmak, A, Cekin, A 2008: Association of Helicobacter pylori and giardiasis in children with recurrent abdominal pain. Turk. Parazitol. Derg. 32:4-7. 